TITLE:

RHYTHMIC ACTIVITY OF THE SEASIDE BARNACLE TETRACLITA SQUAMOSA JAPONICA PILSBRY IN WINTER

AUTHOR(S):

Mori, Syuiti

CITATION:

Mori, Syuiti. RHYTHMIC ACTIVITY OF THE SEASIDE BARNACLE TETRACLITA SQUAMOSA JAPONICA PILSBRY IN WINTER. PUBLICATIONS OF THE SETO MARINE BIOLOGICAL LABORATORY 1961, 9(2):373-378

ISSUE DATE:

1961-12-20

URL:

http://hdl.handle.net/2433/175286

RIGHT: 


\title{
RHYTHMIC ACTIVITY OF THE SEASIDE BARNACLE TETRACLITA SQUAMOSA JAPONICA PILSBRY IN WINTER ${ }^{1)}$
}

\author{
SYUITI MORI \\ Zoological Institute, Kyoto University, Kyoto, Japan
}

With 3 Text-figures

\section{Introduction}

I had already published on the rhythmic activity of the seaside barnacle, Tetraclita squamosa japonica PILSBRy, saying that the rhythmic protruding activity of the feet was controlled by change of light and of water caused by dashing waves, and food had scarcely no relation with normal induction of the said activity (Mori, 1958).

Since then, however, when I visited the natural habitat near the Seto Marine Biological Laboratory of Kyoto University in winter, I noticed that the feature of the activity was somewhat.different from that of observed in summer. Namley, they often protruded their feet in the daytime, which had never been observed in summer.

Are there then really any differences between the mode of the rhythmic activity of summer and of winter? And if any, what are the causes that evoked these differences? In order to solve these questions I performed some natural observations and laboratory experiments, which are described in this paper.

Refferring the literatures, we can find the works performed by SouTHWARD (1955 and 1957). He investigated the relation between cirral acitivity and water temperature, but the standpoint was from purely physiological, and the adaptation problem found among various species distributing from north to south was widely treated. So that I could not find out any literatures concerning directly with such facts as mentioned in the present paper.

The author wishes to express his sincere thanks to Professor H. UTINomI and other members of the Seto Marine Biological Laboratory, who offered many facilities during the course of the work.

1) Contributions from the Seto Marine Biological Laboratory, No. 374.

2) Present address: Otsu Hydrobiological Station, Kyoto University, Otsu, Japan.

Publ. Seto Mar. Biol. Lab., IX (2), 1961. (Article 20) 


\section{Observations at the natural habitat}

Three plots were selected on the rocks near the Laboratory, the numbers of the barnacle inhabited there were 55,50 and 28 respectively. The observation was performed from 13:30 of Jan. 12 to $10: 00$ of 15 . The number of individuals that were protruding the feet was counted at adequate intervals. Water temperature, air temperature, relative humidity, depth of water where the animals inhabited and intensity of light, were measured simultaneously.

Results obtained at the plot No. 1 are illustrated as the representative in Fig. 1.

It can be concluded from this figure and other observations that;

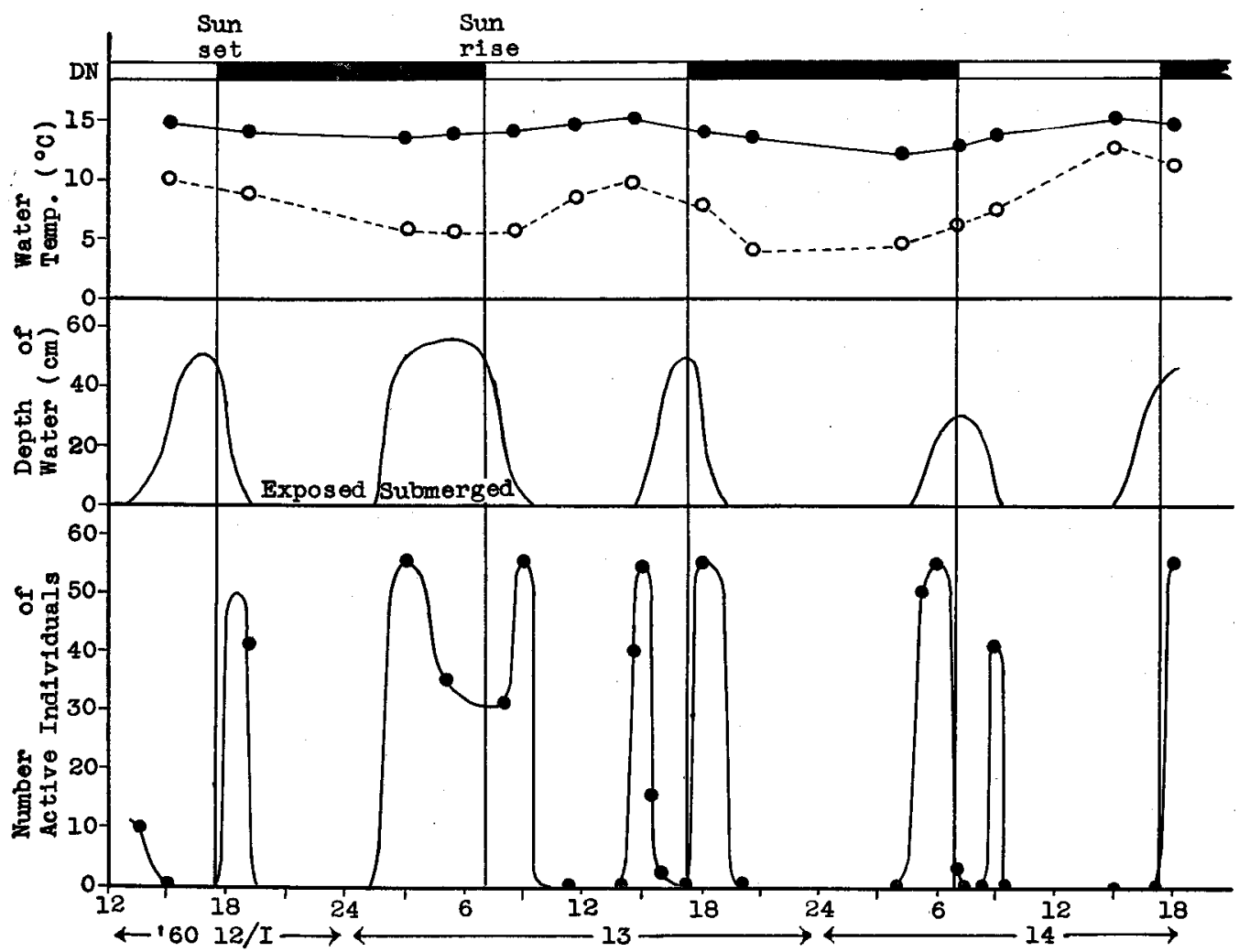

Fig. 1. Daily march of the activity of Tetraclita squamosa, with changes of the physical environments, at the plot No. 1 .

DN : showing day (white span) and night (black span) change.

Upper figure: change of water temperature ( - - ) and air temperature $(\ldots \circ \ldots)$. Note that water temperature is much higher and the change is more stable.

Middle figure: change in depth of water and in period when the barnacles were submerged.

Lower figure: change of activity, indicated by the number of individuals which were protruding actively their feet. 
a) At night: General feature of the activity is similar to that observed in summer. But there seems to occur a slight decrease in activity at the time of the highest flood.

b) In the daytime: When rising water comes and dashing waves wash the animals vigorously they protrude the cirri for a while (more or less 30 minutes) and then close the shells untill night comes when they begin the natural nocturnal activity. However, it must be noticed that in the evening of Jan. 14 they did not show any activity, even when they were washed by the dashing waves, until night came. Two reasons seem to be considered at this time as follows. First, the sea was very calm this evening and consequently the waves did not dash so strongly on the animals that the stimulating agency was insufficient. Secondly, the air temperature was so high that the difference between it and water temperature was not significant as to act as stimulating agency. This last point will be discussed in detail later on. Which of these two causes was importan is not clear at present, but perhaps both might have cooperated.

Then, when the tide is falling and the animals become to be washed by the waves now and then, they begin to protrude the feet; this activity continues also for about 30 minutes, and ceases when the animal body is entirely exposed above water.

c) As environmental conditions of winter which are different from those of summer, we must point out temperature condition. Of coure, temperature is remarkably higher in summer than in winter. And also in summer in the daytime, the water temperature $\left(27-30^{\circ} \mathrm{C}\right)$ is much lower than the air temperature near the surface of rock $\left(27-36^{\circ} \mathrm{C}\right.$, the difference between the two is generally $5-6^{\circ} \mathrm{C}$ ), whereas they are very similar in the nighttime (both about $26-27^{\circ} \mathrm{C}$ ). On the contrary in winter, the water temperature is remarkably higher than the air temperature throughout a day, viz., the former remains between 13 and $15^{\circ} \mathrm{C}$ throughout a day, whereas the latter changes between 4 and $13^{\circ} \mathrm{C}$ (usually below $10^{\circ} \mathrm{C}$ ).

As described above, the different manner of the activity observed between summer and winter seemed to have their cause in the difference of these temperature conditions. The following experiments were planed to make clear this point.

\section{Analysis of behavior by laboratory experiments}

Broken pieces of rock with the attached barnacles (with 80 to 150 individuals) were brought into the laboratory and placed in the glass aquaria under natural light condition. The water was flowed quietly and constantly, and under this condition they never protruded the feet. At adequate intervals they were suddenly subjected to the strong current, which was generated by the water running out 
from a rubber water-pipe. Some of them protruded the feet against the current.

The water temperature was changed as follows. The flowing water was always passed through a long glass tube, which was whirled in the water bath. The temperature of the water in the bath was controlled by the electric heater. so that the temperature of water flowing through the glass tube could be artificially controlled and consequently the environmental temperature of the barnacles could be regulated.

Figs. 2 and 3 show the results. Both the change of water temperature and the number of animals protruded their feet against the current shock are shown.

From these experiments it will be concluded as follows.

a) When the animals, having been subjected to low temperature, are sub-

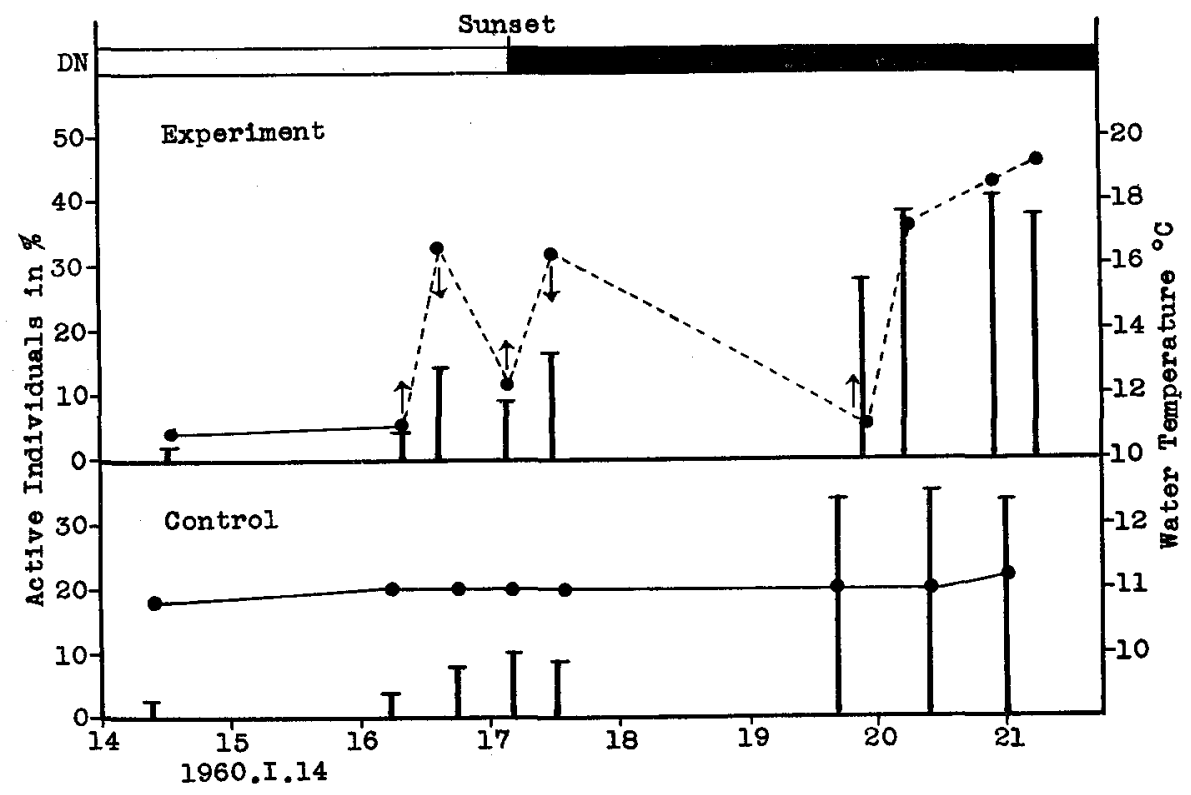

Fig. 2. Change in the protruding activity of the feet against the current shock with the change of water temperature.

Upper figure, experiment, using a piece of rock attached with 91 individuals. Lower figure, control, using a piece of rock attached with 80 individuals.

- - natural change and ..-. - . experimental change of water temperature. Vertical bars show active individuals in percent which protruded the feet when subjected to the strong current. $\uparrow$ indicates the time when water temperature began to rise and $\downarrow$ that when water temperature began to fall. DN shows day and night proceeding.

jected to sudden rise of temperature provided with strong corrent of water, they protrude their feet actively, irrespective of it is in the daytime or in the nighttime. However, the degree of this activation seems to be a little higher at night. 
b) Control animals which have never been experienced the sudden temperature change show the typical summer type of rhythmic activity, that is, the activity is much lower in the daytime than in the nighttime.

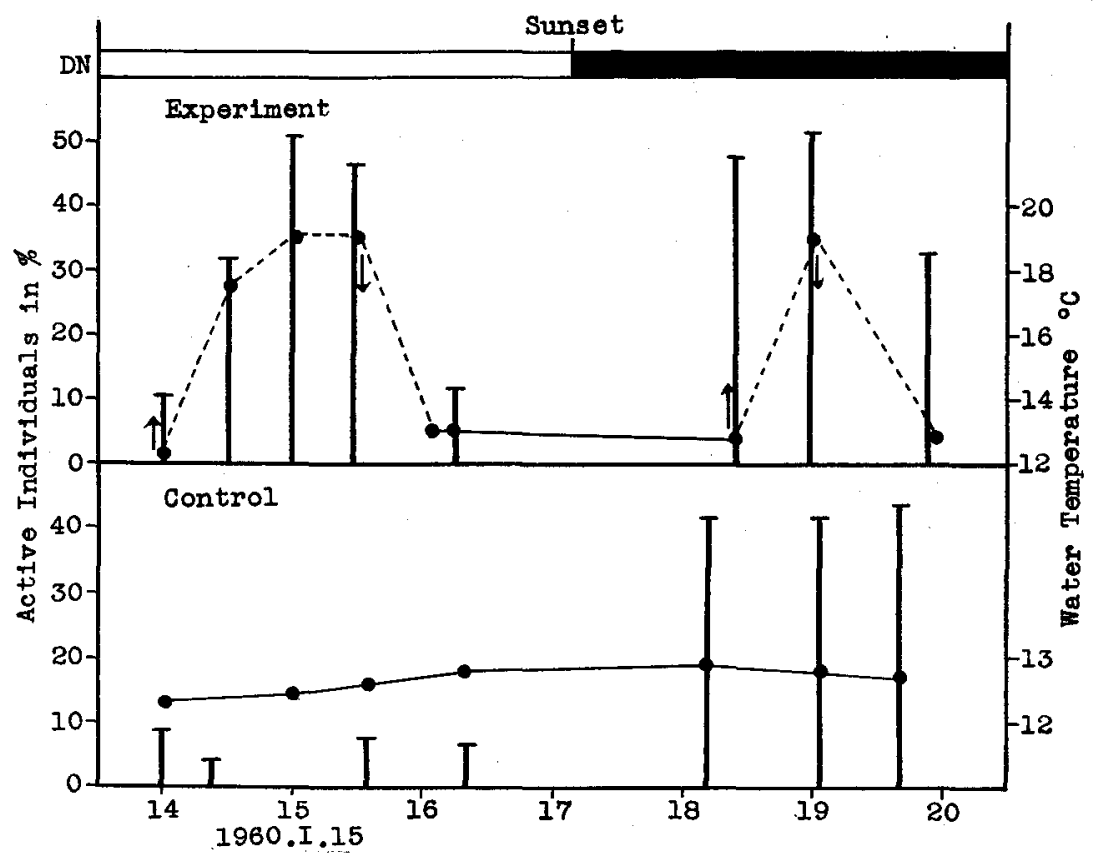

Fig. 3. Same kind of expeirment as Fig. 2. A piece of rock used as experiment was attached with 156 individuals and that used as control was with 147 individuals.

\section{Conclusion}

From above observations and experiments the author considers the causes of daytime activity of the seaside barnacle Tetraclita squamosa japonica PILSBRY in winter, as follows :

The general low temperature, provided with high water temperature relative to the low air temperature is noticeable in winter, and when the water surrounding the animals is going to rise or fall the environmental temperature may change suddenly, and this environmental temperature change together with the strong current caused by dashing waves stimulate the animals to protrude the feet. This behavior usually continues about 30 minutes.

On some hot days in summer the animals will experience the similar kind of temperature change (although the water temperature may be lower than the air temperature), but in this case the animals do not react to this environmental 
chang. So that, in other words, the low temperature seems to lower the inhibitory action of daylight in winter. Of course the stimulation by strong current is always necessary to protrude the feet. Really, on the day of very calm and warm day in winter, they never show this daytime activity, the reason of which may easily be supposed from above consideration. Of course at night, when there is no inhibitory action of light, they show the routine pedal activity so long as they are submerged; however, the degree of the activity seems to decrease slightly at the time of the highest flood, which has never been observed in summer.

\section{LITERATURE CITED}

MORI, S. 1958. Rhythmic activity of the seaside barnacle, Tetraclita squamosa japonica PILSBRY. Mem. Coll. Sci., Univ. Kyoto, Ser. B, 25, 23-30.

SOUTHWARD, A. J. 1955. On the behaviour of barnacles. I. The relation of cirral and other activities to temperature. J. Mar. Biol. Ass. U. K., 34, 403-422.

on cirral activity. Ibid., 36, 325-334. 